\title{
ICSC Problems and Perspectives of high- calcium fly ash from heat power plants in the composition of "green" building materials
}

\author{
Irina Domanskaya ${ }^{1 \mathrm{a}}$, Valentina Oleynik $^{1}$, and Denis Minyazev ${ }^{1}$ \\ ${ }^{1}$ Ural Federal University, Institute of materials science and metallurgy, 620002, Yekaterinburg, \\ Russia
}

\begin{abstract}
The peculiarities of the composition formation and hydraulic activity of high calcium fly ash got by burning of Kansk-Achinsk brown coals have been described. Fly ashes selected in dry state can be used as peculiar (specific) binding agents (minerals) on condition of their preliminary handling reducing nonuniform volume change of the ash stone during hydration and also the expansion range of their application in green building. The cavitation technologies, the organization of the fly ash granulation at heat power plants instead of hydraulic ash removal systems and enrichment by various means to extract rare-earth metals are considered to be the most perspective methods of fly ash conditioning.
\end{abstract}

\section{Introduction}

Realization of Green Building conception which is an integral part of Sustainable Development makes provision for the application of ecologically and economically effective building (construction) materials which are named "green" ones. In present Russia the national systems of ecological certification and marking of the construction product are based on criterium approach as to the analysis of their life cycle proper [1, 2]. When certifing building materials the influence of the whole complex of a number of processes upon environment is valued (appreciated), namely: from extraction of raw materials to means of their processing during the manufacturing process up to complete demolition, landfill and possible recycling [3]. Under such approach a lot of artificial materials fail to bear criticism; the technologies of their production are too expensive for both the society and nature as a whole. Nowadays the most widely used binding material all over the world is Portland cement, also concretes and mortars on its basis. The concern of the world community as to the perspectiveness of cement production development, the share of global $\mathrm{CO}_{2}$ emissions being $5 \%$ caused the active search of alternative binding materials $[4,5]$. Such innovative binding substances are of great practical importance from both ecological point of view and economy because industrial waste are used to produce them instead of the natural raw materials. From our point of view the most perspective base to produce alternative hydraulic (water resistant) binding materials is thermotechnogenic raw material - mineral waste which have suffered different types of high temperature affect to

${ }^{a}$ Corresponding author: i.k.domanskaya@,urfu.ru 
form liquid phase and kept their amorphous structure partially or completely as a result of their prompt cooling. Granulated blast furnace slags from metallurgical industry and fly ashes from heat power plants refer to this group. The present work is devoted to the problems of utilization and perspective trends of high calcium fly ashes conditioning resulting from burning of Siberian brown coals of Kansk-Achinsk basin.

\section{High-calcium fly ash - is a specific type of thermotechnogenetic raw material for production of binders}

Fly ashes is not new source of mineral raw for building industry. For many years they are used in ceramics technology, for fractional substitution of Portland cement in production of concretes and mortars, for creation of geopolymeric and other binders and composites on their bases also [6-10]. Despite long-term experience of study and practical use of flyashes, there is still urgent and constant need to develop new methods of their application because of significant variation of their compositions and properties [7]. A specific problem present high-calcium fly-ashes (HCFA), that appear while burning brown coals and some kinds of slate coals (C class according to ASTM C618-12). As usually they contain 1-40\%, sometimes up to $60 \%$ calcium oxide, including that of in free form, not fixed in chemical compounds ( $\mathrm{CaO}$ free). The $\mathrm{CaO}$ free content in HCFA may vary from 0 to $20 \%$ and more. The presence of free lime $\mathrm{CaO}$ free in fly-ashes, on the one hand, provides them for binding properties and possibility of hardening after hydration. On the other hand, it causes some ecological and technological problems in removal, storage and utilization processes.

\subsection{Composition formation and hydraulic activity of high calcium fly ashes}

Brown coals are defined as "young" ones and they are the subject of much current interest due to their superior form from peat to coal. The share of coal reserves in Russia are accounted for nearly $40 \%$. As to the composition of brown coals the organo-mineral complexes in the form of $\mathrm{Ca}$ and $\mathrm{Mg}$ humate prevail in distinction to coals, but the other metals are rare. Therefore, the mineral unburnt (non-fired) part of the brown coals is represented by assemblage of biogenic origin ashes - the so-called "internal"("parent") ash, its quantity amounts to $70 \%$ and the "external" one including the impurities of the enclosing rocks [11]. Complex physico-chemical processes of the ash residue formation take place during the burning process of this kind of solid fuel resulting in: organo-mineral complexes decay and interaction of the elements released with both the gas phase components and each other, also melting, crystallization from the melt etc. The experimental results of the composition and properties of the 17 fly ash probes got by brown coals torch burning at Berezovsky heat power plant (Krasnoyarsk region), also the thermodynamic calculations and the probable reactions analyses by using the state diagrams $\mathrm{CaO}-\mathrm{Al}_{2} \mathrm{O}_{3}-\mathrm{Fe}_{2} \mathrm{O}_{3}$ carried out earlier have shown the following [12]. It is established that the supposed $\mathrm{CaO}$ isolation from the organic substance $\left(400-600^{\circ} \mathrm{C}\right)$ and its interaction with sulfate component of gas phase is more advantageous thermodynamically. The Gibbs energy for this reaction in oxidative conditions is $280.69 \mathrm{~kJ} / \mathrm{mol}$. Thermodynamically less likely the binding of Cao in the aluminates, silicates and carbonates. With increasing temperature, the possibility of sulfation decreases, and the formation of silicates and aluminates of calcium, judging from the values of the Gibbs energy, increases (Table 1). This is confirmed by the results of chemical analysis (Table 2). The most likely phase crystallizing on melt cooling consisting of more than $33-35 \% \mathrm{CaO}$ is belite, and gelenite consists of less $\mathrm{CaO}$ content. However, the low viscosity indicators of the compositions under investigation in the latter case contribute to the conservation of vitrified state at the 
moment of the fly ash particles cooling down which is confirmed by the X-ray diagram character and is also indicative mainly of puzzolana mechanism of their hardening when mixed with water. $\mathrm{CaO}$ free present in flame burned ashes is likely to be the product of the secondary sulfates decomposition.

Table 1. Data of Gibbs energy calculation [12]

\begin{tabular}{|c|c|c|c|c|c|}
\hline \multirow{2}{*}{ Numbers } & \multirow{2}{*}{ Compounds } & \multicolumn{4}{|c|}{$-\Delta \mathrm{GT}$, кДж / mol/K } \\
\cline { 3 - 6 } & & 600 & 800 & 1000 & 1200 \\
\hline 1. & $\mathrm{CaS0} 4$ & 280.69 & 243.94 & 208.11 & 173.62 \\
\hline 2. & $\mathrm{CaCO} 3$ & 82.80 & 52.47 & 22.97 & -5.79 \\
\hline 3. & $\mathrm{CaO} \cdot \mathrm{SiO} 2$ & 90.17 & 90.63 & 90.97 & - \\
\hline 4. & $2 \mathrm{CaO} \cdot \mathrm{SiO} 2$ & 130.48 & 132.29 & 134.29 & 136.44 \\
\hline 5. & $\mathrm{CaO} \cdot \mathrm{A} 2 \mathrm{O} 3$ & 27.19 & 31.40 & 36.01 & 41.11 \\
\hline 6. & $12 \mathrm{CaO} \cdot 7 \mathrm{~A} 2 \mathrm{O} 3$ & 191.42 & 234.17 & 276.75 & 319.99 \\
\hline 8. & $2 \mathrm{CaO} \cdot \mathrm{Fe} 2 \mathrm{O} 3$ & 61.13 & 68.47 & 75.67 & 82.62 \\
\hline
\end{tabular}

Table 2. Evaluation of chemical composition of fly ashes investigated [12]

\begin{tabular}{|c|c|c|c|}
\hline \multirow{2}{*}{ Oxides } & \multicolumn{3}{|c|}{ Oxides content, \%, for ashes obtained at the temperature, ${ }^{\circ} \mathrm{C}$} \\
\cline { 2 - 4 } & $1600-1700$ & $1350-1400$ & $850-880$ \\
\hline $\mathrm{SiO} 2$ & $23.68-32.22$ & $17.05-4.16$ & $10.18-21.80$ \\
\hline Kvar, \% & 13.74 & 22.68 & 44.05 \\
\hline Al2O 3 & $7.69-10.13$ & $9.36-13.02$ & $7.35-10.88$ \\
\hline Kvar, \% & 12.34 & 13.01 & 16.24 \\
\hline Fe2O 3 & $9.35-11.17$ & $6.87-12.70$ & $5.33-12.87$ \\
\hline Kvar, \% & 7.31 & 23.75 & 32.47 \\
\hline CaO & $33.75-38.82$ & $31.33-43.92$ & 12.24 \\
\hline Kvar, \% & 5.81 & 9.65 & $5.62-3.71$ \\
\hline MgO & $4.52-6.20$ & $4.58-6.97$ & 14.74 \\
\hline Kvar, \% & 12.07 & 13.78 & $6.72-15.14$ \\
\hline SO3 & $2.61-5.94$ & $2.64-12.62$ & 32.35 \\
\hline Kvar, \% & 30.92 & 46.91 & \\
\hline
\end{tabular}

Thus, it can be concluded that the phase composition and the hydraulic activity of highcalcium fly ash depend on their mineral part and the "external": "internal" ratio of ashes, the degree of grinding, temperature, the way of coal burning proper, oxidation-reduction character of gas medium, the duration of the particles stay in the furnace chamber, and the place of sampling in the system of fly-ash trapping [12]. The hardening of the samples on the basis of the binding material without cement is accompanied by expansion which magnitude depends on the $\mathrm{CaO}$ free content, $\mathrm{SO}_{3}$ and the storage conditions. The reason of the expansion proper is nonuniform changing of ash stone volume because of slow 
hydration of high temperature lime form (the so called "overburning") and also the screening effect of sulphoaluminate phases forming on the ash glass phase surface [13]. By this means brown coal ashes in spite of the hydration active phases available ( $\mathrm{CaO}$ free, belite, low-based calcium aluminates, glass-phase) providing their ability to harden cannot be used as binding materials( agents) without the additional processing, neutralizing their destructive potential.

\subsection{Practicable (possible) ways to neutralize the destructive potential of high calcium fly ash}

A great body of information testify that to gain the destructive potential of high calcium fly ash reduction one can use additional grinding, pre-autoclaving, partial hydration in the granulation process with subsequent grinding of the granules obtained. Manufacturing cost of high calcium fly ash activation with the means suggested according to some scientists seems to be higher than the consumption cost of the activated fly ash binder ready for use in the majority of cases. Therefore, the actual utilization volume of the high calcium fly ash in Russia the yield of which amounts to million tones fails to exceed 5\% [14]. In our opinion to solve this serious production process the cavitation technology can be used. The experiments have been carried out demonstrating that the cavitation phenomenon resulting in the formation and collapse of cavities after high-rate run through the system of special obstacles (cavitators) is highly effective for hydrodynamic dispersion and slaking of the CAO free excess in brown coal ashes [15]. We have studied the cavitation effect by ultrasound radiation from magnetostriction transducer having taken fly ash as an example of brown coal burning at Berezovsk heat power plant. The research work has been accomplished at the Chair of Binding Materials and Construction Products Manufacture with the scientific workers of the Atomic Stations and Renewable Energy Sources Chair of the UrFU. The content of $\mathrm{CaO}$ free in the fly ash is $15 \%$. It has been established that under the optimum parameters of the ultrasound treatment (handling) it is possible not only substantially to reduce the ash stone expansion by $50 \%$ when it was cured, but to increase practically by 2 times (twice) the sample strength hardened in normal conditions. As discussed to get maximum positive effect it is necessary to use the activated water-ash suspension proper after ultrasound handling. Its binding potential reduces with time. The results got testify that cavitation effect of ultrasound waves is accompanied with the processes hydration activation of high temperature $\mathrm{CAO}$ free, causes the pozzolana reactions intensification when ash glass phase is involved. By this means the experiments carried out confirm the cavitation processes effectiveness to neutralize the destructive potential of the high calcium fly ashes and the necessity to further investigation of both the ultrasound handling of water ash suspensions for the purpose of their optimizing and the chemical reactions mechanisms taking place in these conditions. This allows the initial data to be justified for the development of the commercial installations-neutralizers of the required power.

\section{Ecological aspects of high calcium fly ashes utilization}

Besides the technological problems (the availability of high temperature CAO free, the variability of the chemical composition) which fail to allow high calcium fly ashes to be used as binding materials on their own, there exist a number of ecological non-solved so far problems complicating the organization of large scale commercial utilization of this kind waste. 


\subsection{Special features of high calcium ash slags removal and storing at heat power plants}

In the majority of cases the heat power plants of the Russian Federation use coal fuel and solid wastes removal is done by using the hydraulic method, namely: fly ashes and slags are mixed with large quantities of water and in the form of a pulp is transported through the sluice discharge pipe -line to the ash dump. In case of the calcium oxide 'increase in ash slag wastes the hydraulic ash removal systems are often broken down because of pipeline "overgrowing" with carbonate accumulation. The dumps to store ash and slag occupy substantial areas of land which are excluded from agricultural alteration of crops and require great costs (expenditure) to keep them in order and are dangerous to the adjacent territories and water reservoirs [16]. Obviously that the question of issue to solve the problem of ash dumps is to eliminate hydraulic ash removal and transform to alternative "dry" systems of ash and slag transportation and storage by using minimum water [9].To improve the ecological situation at heat power plants the science workers of the UrFU together with heat power industry plants offer the system of ash removal with preliminary high calcium ashes granulation. The possibility of the high calcium fly ash dry selection is allowed and its use as specific binding agent (after proper handling). As to fly ash out-ofuse it is suggested to granulate it and in the form of pellets with $10-20 \mathrm{~mm}$ in diameter to keep temporary on the open ground [17]. It is due to such "gentle" system of the ash removal which will be the future of the heat power plant burning the brown coals of the perspective Kansk-Achinsk basin for Russia.

\subsection{Sanitary evaluation of high calcium fly ashes}

Sanitary evaluation of the commercial wastes subjected to utilization in the construction materials industry has to include the whole complex of researches, namely: toxicological, sanitary-chemical, radiological. In addition to the product samples by adding the present type of wastes are to be subjected to the laboratory research [16]. It is established that the brown coals radioactivity of the Kansk-Achinsk basin depends on the deposit, the coal seam depth bedding and, practically, is fully defined by 226 Radii which allows the further production control to be limited by defining only this nuklide [18]. According to the data of many scientists studying the content of the natural radionuclide in the brown coals ash dump wastes (A.G. Andreeva, G.V. Kachaev, S.L. Kraft, S.V. Kurkatov, et al.) in the majority of cases it, does not exceed standardized magnitude for the raw materials 370 becquerels per kilogramme. Therefore, the brown coal fly ash of the dry selection can be used as the raw materials to produce construction materials without limitations on condition of the proper control and the periodicity recommended in every concrete case. As far as the toxicological investigations are concerned one can admit the following. Toxicology of the ashes in question is due to the water soluble alkali compounds and also heavy rare earth metals. Their content and that of the natural radionuklide depend on the deposit and the depth bedding of the coals burnt. Accumulating in ashdump toxic agents threaten the safety of the adjacent territories $[16,18,19]$. At the same time there are means which are successfully tested in the laboratory condition allowing such valuable metals as lantanum, cerium, ytterbium, helium, scandium, vanadium (patents RU 2293134, RU 2138339 , etc.) to be extracted. According to the authors, their extraction can justify expenses to organize the commercial recycling of the dry selection fly ash. 


\section{Summary}

From the stand point of view and careful attitude to the environment, the necessity to utilize high calcium ashslag wastes from heat power stations is beyond question, the most perspective being both high calcium fly ashes of the present yield and those accumulated in the ash disposal, occupying thousand hectares of the cultivated lands and containing million tons of finely dispersed mineral thermotechnogenic raw materials. In each concrete case it is necessary to investigate in detail not only chemico-mineral composition of solid wastes defining the perspective trends of utilization, but also their sanitary characteristics including toxicological, sanitary-chemical and radiological investigations. We suggest to consider all possible variants of this raw material conditioning as the necessary constituent when studying the raw material under review that is preliminary handling to fully realize the technological potential taking into account the requirements of both ecology and economics. As to the high calcium fly ash of the present yield there is no doubt the organization the dry selection is to be done and depending upon the composition $(\mathrm{CaO}$ free content, rare-earth elements) the investigation the advisability of enriching (valuable components extracting) and $\backslash$ or the activation by means of mechanical, ultrasound or chemical handling (modification). Only the complex approach to both the burning technology of the Kansk-Achinsk brown coals and the problem of high calcium fly ash utilization at heat power plants can provide safety and deserving replacement of the natural raw materials by the technogenic ones including the alternative binding materials production. To start the development of the concrete brown coal deposit seems to consider it not only as power source, but as the object containing complex assemblage of organic and mineral raw materials and consequently to develop the most effective complex technologies of their recycling.

\section{References}

1. E.A. Sukhinina, Internet-Vestnik of Volgograd SACU, 1 (31) (2014)

2. A.N. Asaul, Materials of the conference "Effective models and technologies of resource saving, energy saving and environmental management in the construction and housing and communal services" (2014)

3. V.P. Knyazeva, Ecological basis of selection of materials in architectural design (Moscow, 2015)

4. D.N. Huntzingera, T.D. Eatmonb, Journal of Cleaner Production, 17, 668-675 (2009)

5. M.C.G. Juengera, F. Winnefeldb, J.L. Provisc, J.H. Idekerd, Cement and Concrete Research, 41, 1232-1243 (2011)

6. C. Heidrich, H.-J. Feuerborn, A. Weir, Coal Combustion Products: a Global Perspective, (WOCA) Conference, in Lexington, KY (2013)

7. Z.T. Yao, X.S. Ji, P.K. Sarker, J.H. Tang, L.Q. Ge, M.S. Xia, Y.Q. Xi, Earth-Science Reviews, 141, 105-121 (2015)

8. Z. Zhang, J. Provis, A. Reid, H Wang, Construction and Building Materials, 56, 113127 (2014)

9. A.I. Kalachev, Proceedings of the V conference "Ashes from TPPs: removal, transport, processing, landfilling", 41-46 (2014)

10. L.M. Delitsyn, Y.V. Ryabov, A.S. Vlasov, Energy saving, 2, (2014)

11. H.A. Iskhakov, M.M. Kolosova, Bulletin of the Kuzbass STU, 4, 109-111 (2006)

12. I.K. Domanskaya, V.N. Oleinik, Internationale Baustofftagung. Weimar, 1, 10711079 (2006)

13. I.K. Domanskaya, V.N. Oleinik, Internationale Baustofftagung. Weimar, 1, 0817$0822(2009)$

14. Y.A. Nikiforov, D.N. Neyland, Mineral wastes: activation and application in low-rise construction (Krasnoyarsk, 2001) 
15. D.N. Neyland, A.Y. Nikiforov, Hydrodynamic activation and application of ash TPP (Krasnoyarsk, 2003)

16. S.G. Andreeva, Hygienic assessment of waste ash produced during combustion of coals of the Kansk-Achinsk basin: author's abstract on the competition of graduate degree Ph.D. (Kemerovo, 2006)

17. I. Domanskaya, V. Ufimtsev, F. Kapustin, V. Oleynik, WIT Press: Energy Production and Managemente in the 21st Century, 2, 1129-1136 (2014)

18. Y.E. Yudovich, M.P. Katniss, Toxic elements-impurities in fossil coals (2015)

19. L.N. Adeeva, V.F. Borbat, Journal Bulletin of Omsk University, 2, 141-151 (2006) 